\title{
GIS AND LAND HISTORY: THE DOCUMENTATION OF THE ANCIENT AOSTA DUKEDOM
}

\author{
F. Rinaudo ${ }^{\text {a, }}{ }^{*}$, C. Devoti ${ }^{\text {b }}$
}

\begin{abstract}
${ }^{a}$ DAD, Politecnico di Torino, 10125 Viale A. Mattioli 39, Turin, Italy - fulvio.rinaudo@polito.it
\end{abstract}
b DIST, Politecnico di Torino, 10125 Viale A. Mattioli 39, Turin, Italy - chiara.devoti@polito.it

KEY WORDS: CH Documentation, GIS, historical cartography, land history, land planning

\begin{abstract}
:
GIS technology has been recognised as one of the best instruments able to join and relate data coming from different disciplines involved in a documentation process of Cultural Heritage objects. The RecorDIM (Recording, Documentation and Information Management) project defined some general rules to be followed when GIS technology is used to share documentation results among all the possible users (e.g. conservators, restorers, land planners, etc.). The aim of the paper is to show a real application of the proposed rules inside an Interreg III-A (community initiative seeking to favour the harmonious and even development of European territory by encouraging cross-border cooperation) ALCOTRA (Alpi Latine COoperazione TRAnsfrontaliera) project managed by the Italian Valle d'Aosta Region. The Valle d'Aosta Region assigned to the Politecnico di Torino research group (teachers of the High School on Cultural Heritage and Landscape) the goal of placing the results of the archaeological and historical investigations inside a not structured GIS files. This particular approach will allow the integration of the collected data in the regional GIS used for land planning and land risk assessment. This approach required a planning of the recording strategies adopted by the different specialists involved in the project and the structuring of the collected data in a way that could allow the dissemination of the results among all the land planners at every scale (from regional scale up to urban scale). The proposed approach will allow an easy and direct access to the results of historical and archaeological investigations to the specialists involved in the plan of future landscapes and land uses.
\end{abstract}

\section{INTRODUCTION}

One of the main problems in the preservation and conservation of diffused Cultural Heritage assets (e.g. a landscape or a set of settlements) is the basic knowledge that each planner has to consider in order to build up an intervention strategy able to respect the history and the tradition of a place.

The international community defined the new discipline of documentation as a mix of different knowledge which aims to point out the cultural aspects of an asset and to monitor its conservation state and the persistence of the peculiarities which give to the investigated object a cultural meaning; at the same time the problem of communication towards the people involved in decision processes about Cultural Heritage was underlined and some general solutions were proposed (Letellier R., 2007).

In particular the GIS technology was selected by the RecorDIM project as the best instrument to share the results of the documentation process among all the specialists involved in the intervention and management of a Cultural Heritage asset.

One of the main results of RecorDIM in this field was the acceptance that it is not possible to devise a unique and strong solution (e.g. a GIS platform) because of the rapid hardware and software development and of the different ways adopted for the planning of intervention and management actions [Rinaudo F., Bilgin G., 2007].

Something else which does not allow the realisation of a complete GIS project for Cultural Heritage documentation is the wide spectrum of possible Cultural Heritage objects ranging from archaeological sites, architectural objects, urban centres, natural landscapes, etc. Each of these requires different approaches and different data to be managed.

Due to the fact that documentation is a never-ending process which is upgraded each time a real intervention can be foreseen on Cultural Heritage assets, GIS was not conceived just as a repository of data but in a more appropriate way, as a logically structured set of data organised in such a way that they can give significant answers by considering the main aims of the planned actions.

Therefore RecorDIM stopped his proposal to a more general level by indicating some general rules to be respected in order to allow consistent and efficient GIS solutions for each object (e.g. the selection of the important data by analysing the real queries to be solved by the GIS, the use of a unique reference and coordinate systems, the use of the scale concept also for the database structure in terms of level of detail of the provided informations).

In the following sections the project AVER (Ancient Vestiges En Ruine) is presented and the specific goals solved by the Politecnico di Torino group are described by using the data coming from all the specialists involved in the research.

The aim of the paper is not to describe the results from an historical point of view but to show how researchers organised their work and how the GIS planning and realisation allowed a correct representation of the obtained results.

\section{THE AVER PROJECT}

The AVER project is one of the local projects developed under the umbrella of Interreg III-A ALCOTRA initiatives founded by European Community (see Figure 1).

The main aims of the project "Des Montagnes de châteaux AVER (Anciens Vestiges en Ruine)" were the plan of intervention protocols to speed up and control the conservation, restoration and valorisation projects for the castles and fortified structures still present in the Valle d'Aosta (Italy) and HauteSavoie (France) regions. 
The project started by considering some interesting places in both regions where it was still possible to realise some intervention of conservation and valorisation: the ChâteauVieux aux Allinges in France and the two seats of Graines and Saint Marcel castles in Italy.

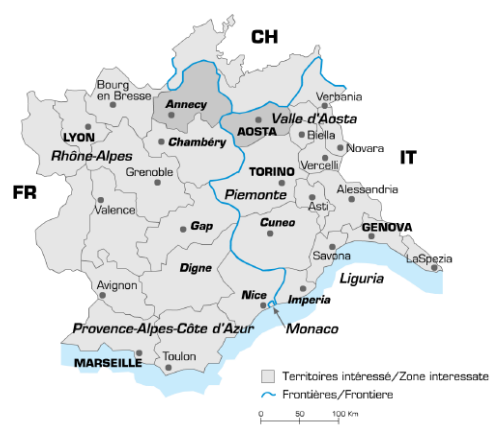

Figure 1. The ALCOTRA project extension (in dark grey the two regions involved in the AVER project)

At the same time the coordinator of the project, Valle d'Aosta region, decided to open the stud

analyse the fortification struciuics as a neıwur virugny different historical periods from the thirteenth century up until today. The main aim of this intervention was to underline past signs of these structures - visible or not visible today but cited by historical records - in order to give to the land planners the possibility to insert the historical knowledge inside the new projects about land use. In this they would be respecting the historical visible and not visible cultural meanings and to allow valorisation projects by the different agencies acting on the Valle d'Aosta region starting from a common knowledge dataset.

The results of the project (archaeological, historical and technical) have been presented at the end of 2012 in Aosta [AA.VV, 2012].

\subsection{The Politecnico di Torino activity}

The aforementioned land historical research was assigned to a group of teachers belonging to the high school on Cultural Heritage and Landscape (Scuola di Specializzazione in Beni Architettonici e del Paesaggio) of the Politecnico di Torino.

The research group concentrated its efforts on the analysis of historical maps, archaeological and historical records, field inspections, readings of the English and foreigners' travel memoires of the nineteenth century.

All the acquired data and information have been collected and compared in order to organise a complete scenario of the development of the fortified structures and connections in the old Aosta Dukedom during its transformation into an area of the Italy Reign (1861-1945) and, finally, as a region of the Italian Republic (from 1946 until today).

All the researchers provide georeferenced data, deep analysis and reports to demonstrate the final results and the possible valorisation actions to preserve traces of this historical phenomenon. In this way future generations will be given a way to provide the inhabitants and the visitors an alternative point of view of the Valle d'Aosta region.

To merge the different results achieved by the specialists an $a d$ hoc GIS has been developed, able to allow spatial intersections between the collected data to help the specialists to analyse in a more integrated way the obtained results.

The AVER-GIS solution has been conceived in such a way that at the end of the project the Valle d'Aosta region can upload in a quick and correct way the results of the investigations inside its own regional GIS and superimpose these results inside all the inquiries performed by the specialists and/or simple visitors. In the following paragraphs the structure of the realised GIS will be explained and justified.

The adopted GIS platform is the ESRI ArcMap 10.0, a choice determined by the factbecause that Valle d'Aosta Region uses this platform as official GIS interface for all the land data.

\section{THE INVESTIGATION STRATEGIES}

The full historical investigation (bearing in mind the analysis had to be compared with a modern assessment) has been split into different main themes:

- viability;

- hydrography;

- land ownerships;

- castles and fortification structures;

- visitors itineraries and visited places.

At the beginning of the investigation all the specialists defined the topics of their researches and shared with all the involved people the basic used documents (maps, archives, field inspections, etc.), the object of the investigations and the set of attributes to be defined for each of them.

By considering the extension of the analysed territory and the detail of the foreseen results, the 1:50.000 scale was fixed as reference scale for the GIS.

\subsection{Cartographic dataset}

The 1:50.000 scale map of the Valle d'Aosta region was adopted. As all the Italian official cartography from 2011, the reference system adopted in all the GIS of the Valle d'Aosta region, is the WGS84- ETRF00 and the cartographic system, the UTM.

All the collected data have been connected to this system in order to guarantee transportability in all the official datasets for land planning.

Therefore, due to the adopted convention, all the objects will have the positioning accuracy higher or equal to the 1:50.000 scale (e.g. $\pm 10 \mathrm{~m}$ ). The field inspections have been realised by using updated or historical maps with scales higher or equal to 1:50.000 or GNSS systems used in the absolute positioning approach.

The possibility of increasing the scale map (e.g. to represent the graphical results of the research inside maps with higher scales) can be reached by locating the objects with more accurate positioning systems or by interpreting the new locations of the objects themselves.

\subsection{Viability}

The analysis of the development of the viability infrastructures has been performed by using all the cartographic sources extracted from Italian and French archives and the most updated Italian cartographic dataset, considering the roads' net as the natural connection between different strategic (i.e. castles and fortifications) land points and settlements.

The historical maps were shared, as usual, between all the researchers involved into the analysis, asking each of them to retrace the different aspects underlined by the same drawing (i.e. settlements, traces of the ancient political organisation, cultural landmarks, and, obviously the road system itself).

The maps range from the second half of the eighteenth century up to 2010 and most of them are not referred to the used 
cartographic system.

In some cases (geodetic maps produced after 1840) it was possible to superimpose the UTM/WGS84 grid but in some other cases this was not possible due to the lack of sufficient information (e.g. homologous points between present and old maps. See Figures 2 and 3).

Five different historical periods (1800-1830, 1831-1860, 1861$1930,1931-1950,2012$ ) were analysed by the specialists, corresponding not merely to the age of the different cartographic bases, but to historical sections indicating capital transformations on the land structural organisation and connecting the Medieval or Modern age of the castles and fortifications to the contemporary roads net.

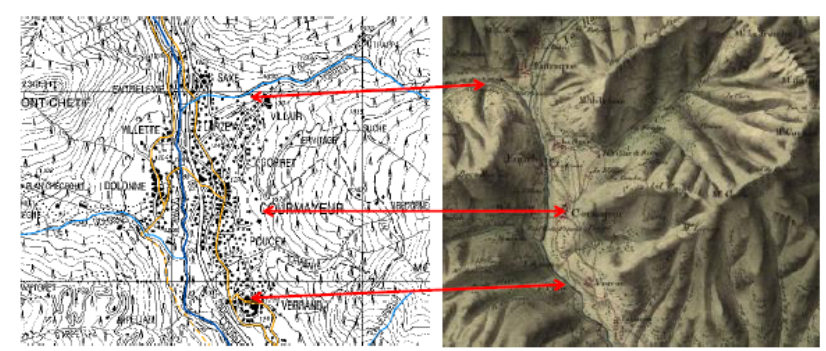

Figure 2. Georeferencing of historical maps in the cartographic system by using homologous points

For each period some basic attributes were characterised: typology, epoch, class and identifiability.

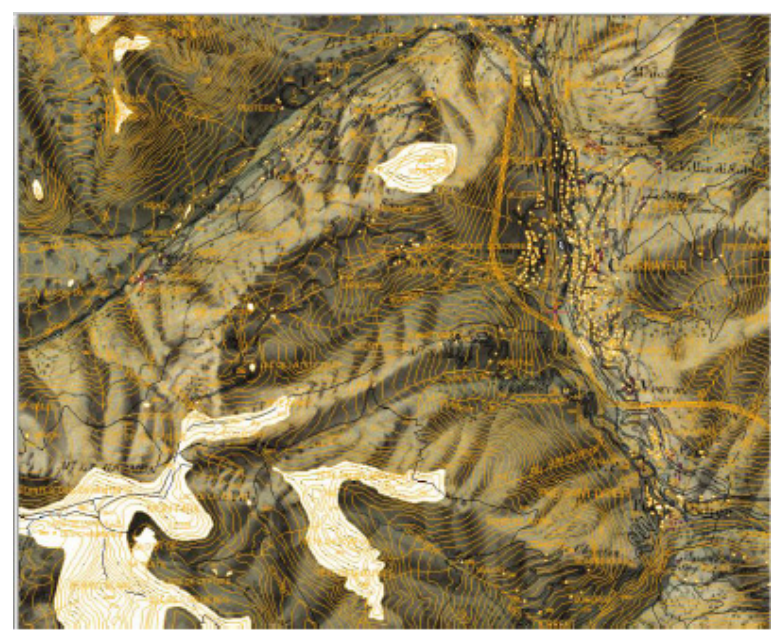

Figure 3. Superimposition of historical and present maps for diachronic analysis

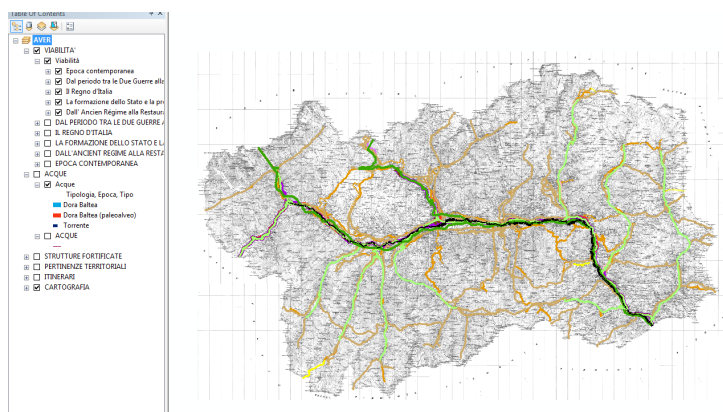

Figure 4. Viability in the different epochs

The researchers also defined the symbols to be used to correctly represent the extracted objects in order to fit their own disciplinary conventions (see Figures 4 and 5).

Roads have been recorded as polylines or directly inside the GIS platform when historical maps have been georeferenced to the present cartographic system or manually on the old maps than transposed inside the GIS by using a standard digitalisation procedure.

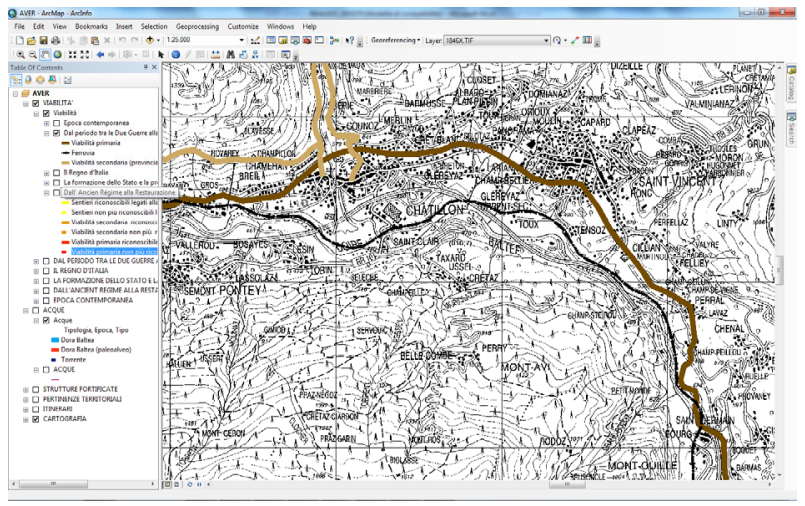

Figure 5. Main roads (dark brown), secondary roads (light brown) and railways (black) in the period between the two World Wars

\subsection{Hydrography}

The hydrography in the Valle d'Aosta region can be studied by using the most updated maps because of the morphology of the land (see Figure 6).

By considering the fact that more than $95 \%$ of the investigated area is formed by hard course-grained rocks one will appreciate that the creeks and the river (Dora Baltea) did not change their ways during the time (inside the accuracy of the scale adopted). By comparing historical cartography and recent maps only the main river shows some way variations (see Figures 7 and 8) due to the alluvial properties of the crossed land.

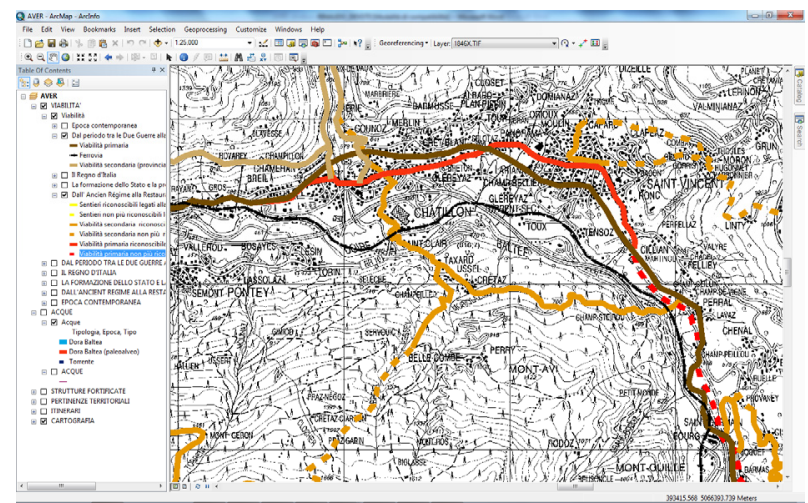

Figure 6. Diachronic visualisation of selected data in the same area of figure 5 (red and yellow continuous lines are the still visible roads and dotted lines are not visible today but visible

on historical maps at the end of the eighteenth century)

\subsection{Land ownerships}

Land ownerships have been recorded as polygons and just a single attribute was defined (e.g. the name of the family) just to show the different possessions during two main historical periods: the thirteenth and fifteenth centuries. After this date all the Valle d'Aosta Region (Aosta Dukedom) was under the Savoy dynasty and subsequently under the ownership of the 
Italian republics.

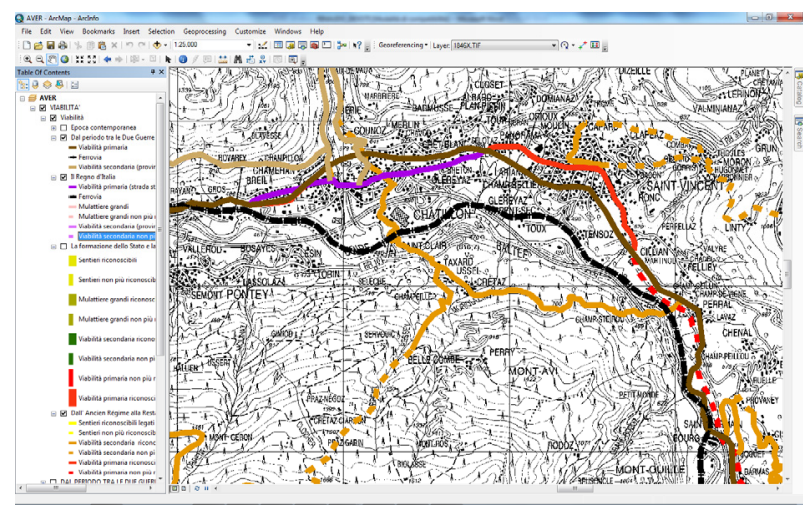

Figure 7. Three different historical periods compared to understand the transportation road changes

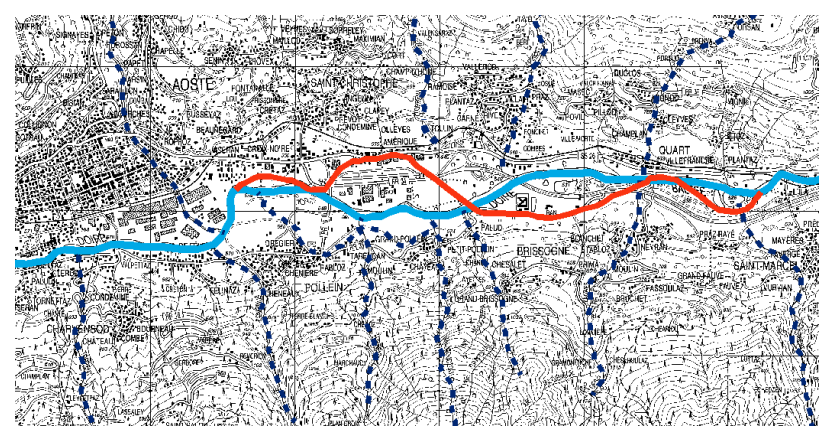

Figure 8. The Dora Baltea river present way (cyan) and old way (red). The dark-blue dotted lines represents the creeks

In this case the GIS planners comply with researchers decisions; also, if the periods don't have any apparently visible link to the viability historical periodization, the different layers can be used also in a separate way for different purposes and therefore the homogeneity of the timescales can be overpassed (see Figure 9).

We must consider that, in Alpine regions, the road system has been maintained unchanged for centuries, so the same organisation can be retraced from the very long Middle age period to the second half of the eighteenth century, creating therefore there is a direct connection between the different periods. Specifically, historical analysis experience demonstrates that eighteenth century cartography, used as the upper point of the historical scale in this case, is able to combine in itself all the minimal transformations introduced from the Roman age to the late Modern age, providing all the data we could request.

\subsection{Castles and fortification structures}

In this theme the objects have been recorded as single points because of the adopted scale.

The structures have been recognised in three historical sections: at the middle of the eighteenth century, during the fifteenth century and during the Modern Age, reflecting the changing role of the castles and of the fortifications themselves, in accordance with the transformation of the political organisation of the area and the increasing importance of the Ducal and then Royal Family of Savoy as controller of the Alpine passes.

Each point has been characterised by using seven different attributes: typology, visibility, existence in previous periods, land ownership; attested name, number (used to connect the historical report) and synchronic place names (see Figure 10).

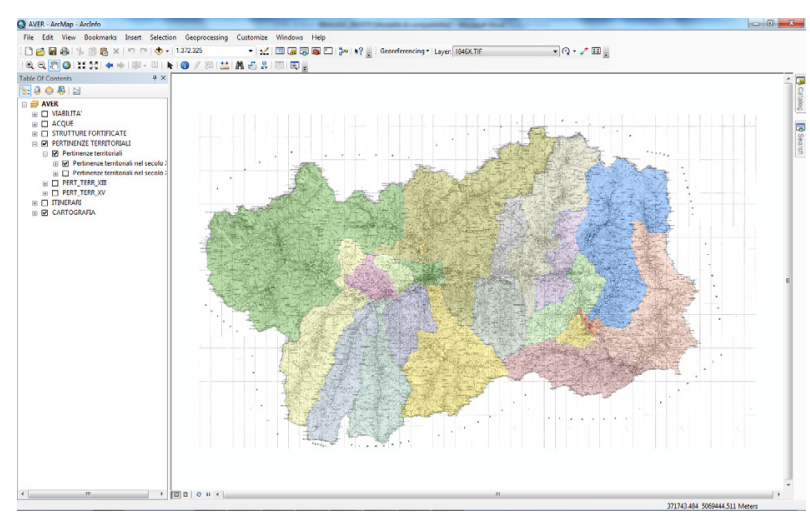

Figure 9. Land ownerships during the thirteenth century

The third and fourth attributes have been automatically generated by using a spatial intersection trough other layers (e.g. land ownerships and previous castle and fortification structures layers).

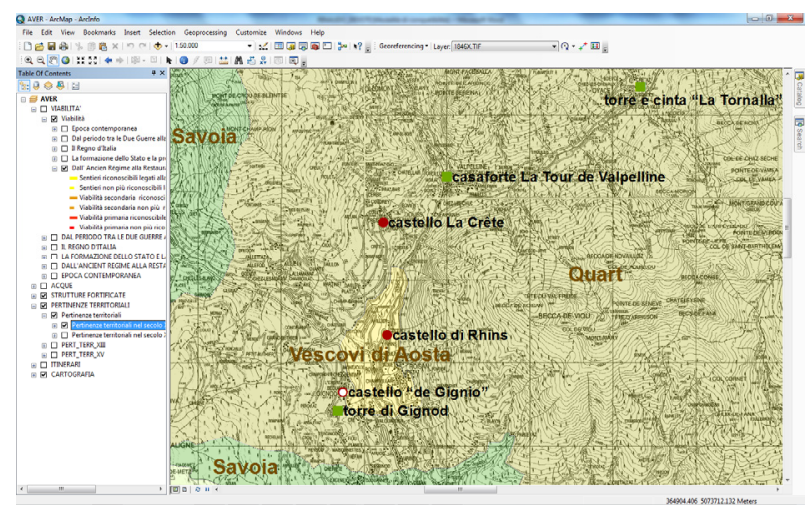

Figure 10. Castles and fortification structures in the eighteenth century (full symbols are structure still visible, empty symbols are structures just recorded on historical archives)

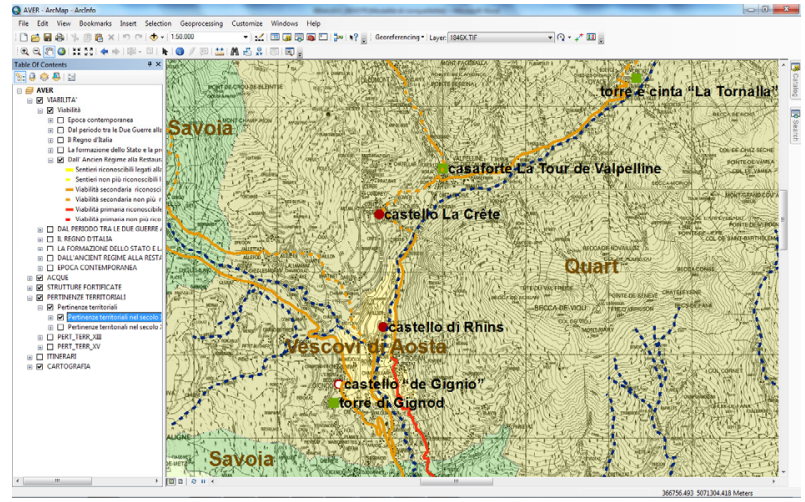

Figure 11. Superimposition of four different layers coming from four different researchers (hydrology, viability, land ownerships and castles)

The different researchers used the GIS platform to analyse their data and to share their results with other specialists. The adopted decision to build up the GIS during the two years of work allows the people involved to use the GIS as a working instrument to visualise in different ways their own data and to 
bridge their information with others specialists to better understand and justify historical events in an interdisciplinary context (see Figure 11).

\subsection{Visitors itineraries and visited places}

The theme related to the readings of the reports and memoires of English travellers during the nineteenth century (with some French cases) has been recorded in two different layers: one related to the journeys (recorded as polylines and combined with the road system recognised for the period) and the second one related to the places about which the visitors wrote personal sensations (recorded as points). To those points some extracts of the personal impressions and some pictures (prints or sketches of the same periods) have been linked in order to allow a first understanding of the personal suggestions of the landscapes (see Figures 12 and 13).

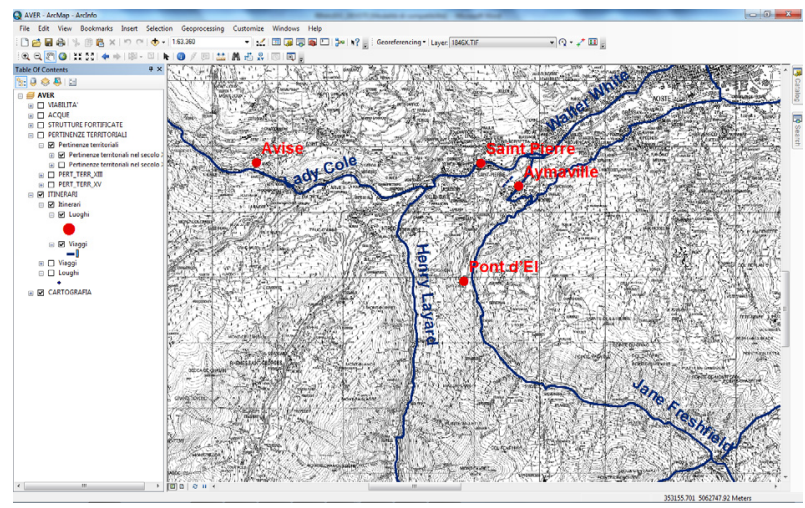

Figure 12. Journeys and travellers (in blue) and visited places (in red)
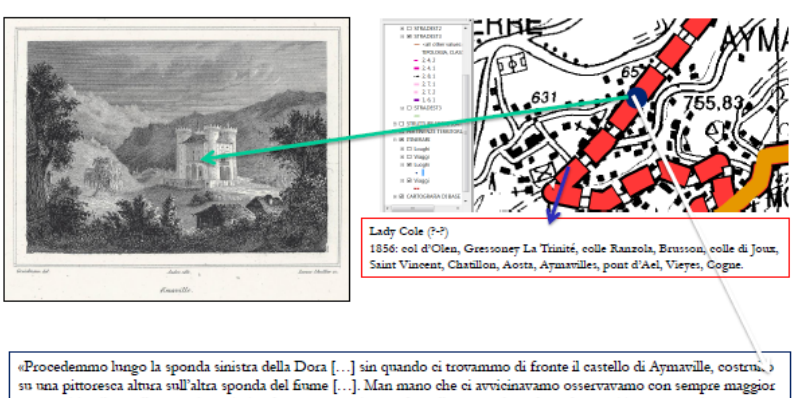

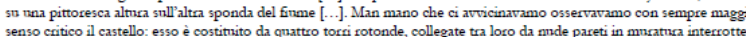
soltanto da apertuse per le finestre. L'efferto generale è decisamente negativon.
(Lady Cole, 1858, cfr Malvezzi, p. 415-410)

Figure 13. Visible links for each interesting place: synchronic prints, journey itinerary, visitor and personal impressions

\section{COMMENTS ON ADOPTED STRATEGIES}

The main goals of the GIS implementation in the AVER project were:

- sharing of the data between the researchers during the historical analysis;

- collecting of all the data in a unique coordinate/reference system;

- giving the possibility to intersect the data coming from different analysis;

- build-up a set of layers able to be inserted in the main GIS environment of the Valle d'Aosta Region.

The GIS technology has been introduced from the beginning of the research therefore all the involved specialists faced the problems to be solved before the collection and analysis of the data (historical maps, present maps and historical documents and records).

This is an important aspect of the GIS implementation for Cultural Heritage Documentation which forces the involved specialists to participate actively in the GIS design and to use it in order to establish whether the inserted data are correctly interpreted and represented. The possibility to access the GIS platform during the collection of the data helped the researchers to check the real extension of the datasets, to check the completeness of the datasets and to verify the attribute characterisation for each object.

The input of the data during the whole development of the research also allows for the sharing of partial results among the specialists and therefore the possibility of each of them to verify hypotheses, possible scenarios, and to correct, if it is the case, the follow on of the researches themselves.

The adopted attribute structure reflects the scale map chosen for the GIS (e.g. 1:50.000) and can be expanded on request by considering the final results of the researches. The efforts to keep the attribute structure essential and simple are a possible way to ease the interpretation of the results by different skilled people who have to use those results as a basis for their works. Also, if the investigations are full of information and results, the main efforts in the AVER GIS design have been directed to the highlighting of the fundamental and essential results which can influence land planner decisions and to offer more information and more deep analysis out of the GIS structure by using traditional reports and/or thematic maps.

All the produced layers will be inserted inside the new WegGIS of the Valle d'Aosta region (the so-called Sistema delle Conoscenze Territoriali-and knowledge System). This was adopted by the local authorities as the unique official storage platform of the data, which allows accurate knowledge and comprehension of the region for all the specialists who will work on land planning, and valorisation of Cultural Heritage assets (single monuments, thematic corridors, etc.).

\section{CONCLUSIONS}

The AVER project enabled the verification of the correctness of the RecorDIM approach to GIS implementation for Cultural Heritage documentation in a specific case, a historical landscape.

The main aspect that has been confirmed is the extension of the concept of the "scale map" to "the scale of the database" connected to the cartographic dataset.

The "density" of the non cartographic information has to be balanced in order to respect the level of detail of a traditional cartographic product: in cartographic theory the level of detail is interpreted as the minimum size of the object which can be inserted inside the cartography by respecting the congruence of the representation.

The extension of the scale concept force to adjust the attribute structure in order to guarantee the readability of the GIS by people with different skills.

The real participation of all the specialists to the GIS design allows us to generate not only a repository of the final achieved results but also a shared instrument to develop a coherent multidisciplinary study of a huge historical phenomenon approached by using different points of view finalised to a common goal. 


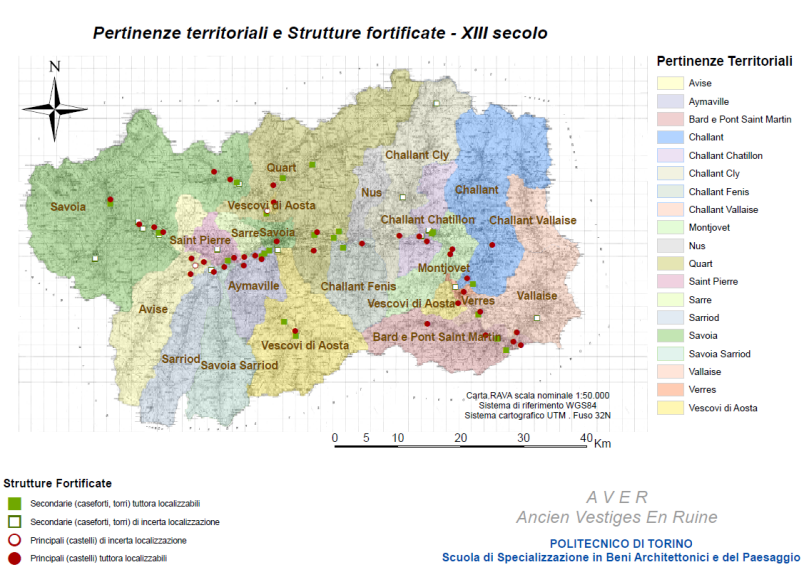

Figure 14. Thematic map of the land ownerships and castles in the thirteenth century

The realised GIS layers allow a possible inquiry of all the aspects related to a huge historical period when the fortress and castles played a fundamental role into the development of the land structure that can be preserved and valorised; also, if land planning and land protection policies require heavy modification of existing infrastructures such as roads, railways and rivers.

\section{References}

AA.VV., 2012. AVER - Anciens vestiges en ruine, colloque de cloture. ISBN 9788890546754

Aliprandi L.G., 2011 - La cartografia degli Stati sardi dopo le carte di Borgonio (1680) e Stagnone (1772) sino all'Unità d'Italia La Vallée d'Aoste sur la scène. Cartografia e arte del governo, 1680-1860, catalogo della mostra, 24 ORE cultura, pp. 39-51.

Antonson, H., Gustafsson, M., \& Angelstam, P., 2010 - Cultural heritage connectivity. A tool for EIA in transportation infrastructure planning. Transportation Research Part D: Transport and Environment, 15(8), 463-472.

Barak, M., Herscoviz, O., Kaberman, Z., \& Dori, Y. J., 2009 MOSAICA: A web-2.0 based system for the preservation and presentation of cultural heritage. Computers \& Education, 53(3), 841-852.

Berg, E., 2012 - The Use of GIS in the National System for Cultural Heritage Management and Dissemination to the General Public in Norway: Case Study: The Heritage Management Database "Askeladden" and the System for Dissemination to the Public, "Kulturminnesøk". In Progress in Cultural Heritage Preservation (pp. 578-585). Springer Berlin Heidelberg.

Curtis, C., 2012 - Planning for Heritage Preservation in Western Turkey: a GIS Approach to Archaeotourism and Agricultural Policy. Chronika, Volume II, 42.
Devoti C., 2011 - I detentori della "langue de la terre": misuratori, topografi e cartografi del regno sardo (1683-1860), La Vallée d'Aoste sur la scène. Cartografia e arte del governo, 1680-1860, catalogo della mostra, 24 ORE cultura, pp.53-59.

Fan, L. I., 2008 - Application and Perspective of GIS in Research on Historical Geography and Cultural Geography [J]. Geography and Geo-Information Science, 1, 007.

Gaitatzes, A., Christopoulos, D., \& Roussou, M., 2001 Reviving the past: cultural heritage meets virtual reality. Proceedings of the 2001 conference on Virtual reality, archeology, and cultural heritage (pp. 103-110).

Gorret A., Bich C., 1877 - Guide de la Vallée d'Aoste. Casanova.

Ioannides, M., Fritsch, D., \& Leissner, J. (Eds.), 2012 Progress in Cultural Heritage Preservation(Vol. 7616). Springer. ISBN 978-3-642-34233-2.

Letellier R., 2007 - Recording, Documentation, and Information Management for the Conservation of Heritage Places: Guiding Principles. J.P.Getty Trust. ISBN 978-0-89236-925-6

Malvezzi P., 1972 - Viaggiatori inglesi in Valle d'Aosta. Edizioni di Comunità.

Meyer, É., Grussenmeyer, P., Perrin, J. P., Durand, A., \& Drap, P., 2007 - A web information system for the management and the dissemination of Cultural Heritage data. Journal of Cultural Heritage, 8(4), 396-411.

Palang, H., \& Fry, G., 2003 - Landscape interfaces: Cultural heritage in changing landscapes (Vol. 1). Kluwer Academic Pub. -ISBN 1-4020-1437-6

Rinaudo F., Bilgin G., 2007 - RecorDIM Task Group 9: Generic GIS template for the management of heritage Objects. -http://cipa.icomos.org/index.php?id=41 (10 Apr. 2013)

Swensen, G., \& Jerpåsen, G. B., 2008 - Cultural heritage in suburban landscape planning: A case study in Southern Norway. Landscape and urban planning, 87(4), 289-300.

Torres, J. C., López, L., Romo, C., \& Soler, F., 2012 - An information system to analize cultural heritage information. Progress in Cultural Heritage Preservation (pp. 809-816). Springer Berlin Heidelberg.

Viglino Davico, M., Devoti C., 2008 - Aspetti dell'età moderna nell'architettura valdostana (secoli XVI-XVIII) in S. Noto (a cura di), "La Valle d'Aosta e l'Europa", Leo S. Olschki 2 voll., I, pp. 293-331.

Viglino Davico M., Zannoni F., 2011 - La difesa del territorio, in La Vallée d'Aoste sur la scène. Cartografia e arte del governo, 1680-1860, catalogo della mostra, 24 ORE cultura, pp. 121-125.

\section{Acknowledgments}

Micaela Viglino, Claudia Bonardi, Vittorio Defabiani, Laura Palmucci, historical researchers; Sarah Braccio, GIS experts; Valle d'Aosta Region, coordinator of the AVER project. 